\title{
OLESAN MINYAK ZAITUN MENGURANGI DERAJAT RUAM POPOK PADA ANAK 0-24 BULAN
}

\author{
Wanodya Hapsari, Fajaria Nur Aini \\ Poltekkes Kemenkes Semarang \\ Email:bidanona@yahoo.co.id
}

\begin{abstract}
This study was to determine the reduction in the degree of diaper rash with olive oil spread. Problems that are often found onthe baby's skin are diaper rash and are associated with external irritants such as dirt, material from diapers, urine, microorganisms, and friction caused by diapers and recur. The incidence of diaper rash in Indonesia reaches 7-35\% which afflicts boys and girls under three years old. Non-pharmacological therapy in diaper rash, which is to eliminate or reduce skin moisture and friction by replacing diapers according to capacity, applying olive oil that contains antioxidants in high amounts of vitamin $E$ ( $\alpha$-tocopherol) and phenolic compounds.

The design of this study was quasi-experimental, with a sample of 22 infants divided into 2 groups, each with 11 diapers rashes smeared with olive oil and 11 other infants using only cloth diapers that were changed every time they were wet, finished chapter and tub. The population in this study were children aged 0-24 months who experienced diaper rash. The sampling technique in this study uses a non-probability sampling method with a purposive sampling technique. Analysis with Wilcoxon statistical tests.

The results of the study showed a significant difference between the spread of olive oil and the use of cloth diapers on the degree of diaper rash with a significant number of 0.007 at $p<0.05$.
\end{abstract}

Keywords: diaper rash; olive oil, non-farmacolog, diapers

\begin{abstract}
ABSTRAK
Penelitian ini adalah untuk mengetahui pengurangan derajat ruam popok dengan olesan minyak zaitun .Masalah pada kulit bayi yang sering ditemukan adalah ruam popok dan berhubungan dengan iritasi eksternal seperti kotoran, bahan dari popok, urine, mikroorganisme dan gesekan yang disebabkan oleh popok dan terjadi berulang. Di Indonesia bayi laki-laki dan perempuan yang berumur kurang dari tiga tahun, mengalami ruam popok sekitar $7-35 \%$. Terapi non farmakologi pada ruam popok yaitu menghilangkan atau mengurangi kelembaban dan gesekan kulit dengan mengganti diapers sesuai daya tampung, mengoleskan minyak zaitun yang mengandung antioksidan dalam jumlah tinggi vitamin $\mathrm{E}$ (a-tokoferol) dan senyawa fenolik.

Desain penelitian ini quasi eksperiment, dengan sampel sebanyak 22 orang bayi dibagi menjadi 2 kelompok, masing - masing 11 orang bayi dengan ruam popok diolesi minyak zaitun dan 11 orang bayi lainnya hanya menggunakan popok kain yang diganti setiap kali basah, habis bab dan bak. Populasi pada penelitian ini adalah anak usia 0-24 bulan yang mengalami ruam popok. Teknik pengambilan sampel dalam penelitian in menggunakan metode non probability sampling dengan teknik purposive sampling. Analisis dengan uji statistik Wilcoxon.

Hasil penelitian ada perbedaan bermakna antara olesan minyak zaitun dan penggunaan popok kain terhadap derajat ruam popok dengan angka significancy 0.007 pada nilai $\mathrm{p}<0.05$.
\end{abstract}

Kata Kunci: ruam popok; minyak zaitun, non farmakologi, popok kain 


\section{Pendahuluan}

Masalah pada kulit bayi yang sering ditemukan diantaranya adalah ruam popok, dan biasanya berhubungan dengan iritasi eksternal seperti kotoran, bahan dari popok, urine, mikroorganisme dan gesekan yang disebabkan oleh popok serta biasanya ruam popok ini terjadi berulang (Yonezawa, Haruna, Shiraishi, Matsuzaki, \& Sanada, 2014). Di Indonesia bayi laki-laki dan perempuan yang berumur kurang dari tiga tahun, mengalami ruam popok sekitar $7-35 \%$ (Aisyah, 2018). Studi di Inggris menyebutkan bahwa prevalensi ruam popok selama 4 minggu kehidupan adalah $25 \%$, sedangkan pada anak usia 9 sampai dengan 24 bulan dengan jenis kelamin laki-laki dan perempuan sebesar 16\%-70\% (Blume Peytavi et al., 2014). Selama ini ruam popok diobati dan dicegah dengan terapi farmakologi dengan memberikan salep seng oksida (zinc oxide) dan salep / injeksi kortikosteroid dan untuk terapi non farmakologi yaitu dengan cara mengganti diapers sesuai daya tampung untuk meminimalisir kelembaban dan gesekan kulit, memberikan olesan minyak zaitun dikarenakan kadungan emolien yang ada pada minyak zaitun memberikan manfaat untuk menjaga kondisi kulit yang rusak seperti psoriaris dan eksim. Hasil penelitian meyebutkan bahwa ruam popok jarang terjadi jika menggunakan popok kain yang berjenis baik (Lokanata, 2004).

\section{Metode Penelitian}

Penelitian ini menggunakan quasi -experimental design. Bayi yang mempunyai kriteria sebagai sampel sebanyak 22 orang bayi dibagi menjadi 2 kelompok, masing masing 11 orang bayi dengan ruam popok diolesi minyak zaitun dan 11 orang bayi lainnya hanya menggunakan popok kain yang diganti setiap kali basah, habis bab dan bak yang berlokasi di Ruang Cempaka RSUD Goetheng Tarunadibrata Purbalingga dengan waktu penelitian September s.d November 2017 dengan populasi penelitian adalah anak berumur 0-24 bulan yang mengalami ruam popok. Teknik pengambilan sampel menggunakan non probability sampling dengan purposive sampling. Analisis yang digunakan adalah Univariat dan Analisis Bivariat dengan uji statistik Wilcoxon.

\section{Hasil dan Pembahasan}

Hasil penelitian terhadap 22 responden tentang perbedaan olesan minyak zaitun dan penggunaan popok kain terhadap derajat ruam popok pada anak 0-24 bulan adalah :

1. Analisis Univariat

Tabel 1

Distribusi Responden Menurut Umur

\begin{tabular}{ccc}
\hline Umur (Bulan) & Frekuensi & Presentase (\%) \\
\hline 2 & 4 & 18.2 \\
\hline 4 & 1 & 4.5 \\
\hline 8 & 3 & 13.6 \\
\hline 10 & 1 & 4.5 \\
\hline 12 & 6 & 27.3 \\
\hline 20 & 1 & 4.5 \\
\hline 24 & 6 & 27.3 \\
\hline Total & 22 & 100.0 \\
\hline
\end{tabular}

Berdasarkan table 1, sebagian besar responden berusia 12 bulan (27.3\%) dan 24 bulan $(27.3 \%)$ sedangkan usia 2 bulan (18.2\%), 8 bulan (13.6\%), dan usia 4, 10, 20 bulan anak (4.5\%).

Tabel 2

Distribusi Responden Menurut Jenis Kelamin

\begin{tabular}{ccc}
\hline Jenis Kelamin & Frekuensi & Presentase $(\%)$ \\
\hline Laki-laki & 12 & 54.5 \\
\hline Perempuan & 10 & 45.5 \\
\hline Total & 22 & 100.0 \\
\hline
\end{tabular}

Berdasarkan table 2, sebagian besar responden berjenis kelamin laki-laki yaitu 12 anak $(54.5 \%)$ sedangkan yang berjenis kelamin perempuan 10 anak (45.5\%).

Tabel 3

Distribusi Derajat Ruam Popok Sebelum Dioles Minyak Zaitun

\begin{tabular}{ccccc}
\hline $\begin{array}{c}\text { Derajat } \\
\text { Ruam } \\
\text { Popok }\end{array}$ & \multicolumn{2}{c}{ Eksperimen } & \multicolumn{2}{c}{ Kontrol } \\
\cline { 2 - 5 } & Frek & $\begin{array}{c}\text { Presentase } \\
(\%)\end{array}$ & Frek & $\begin{array}{c}\text { Presentase } \\
(\%)\end{array}$ \\
\hline $\begin{array}{c}\text { Ringan/ } \\
\text { Sedang }\end{array}$ & 7 & 63.6 & 10 & 90.9 \\
\hline Sedang & 4 & 36.4 & 0 & 0 \\
\hline $\begin{array}{c}\text { Sedang/ } \\
\text { Berat }\end{array}$ & 0 & 0 & 1 & 9.1 \\
\hline Total & 11 & 100.0 & 11 & 100.0 \\
\hline
\end{tabular}

Berdasarkan table 3, pada kelompok eksperimen sebagian besar responden sebelum dioles minyak zaitun mengalami derajat ruam popok yaitu ringan/sedang 7 anak $(63.6 \%)$ dan derajat ruam popok sedang 4 anak (36.4\%). Sedangkan pada kelompok control sebagian besar responden 
sebelum dioles minyak zaitun mengalami derajat ruam popok yaitu ringan/sedang 10 anak $(90.9 \%)$ dan sedang/berat 1 anak $(9.1 \%)$.

Tabel 4

Distribusi Derajat Ruam Popok Sesudah Dioles Minyak Zaitun

\begin{tabular}{|c|c|c|c|c|}
\hline \multirow{2}{*}{$\begin{array}{l}\text { Derajat } \\
\text { Ruam } \\
\text { Popok }\end{array}$} & \multicolumn{3}{|c|}{ Eksperimen } & \multirow{2}{*}{$\begin{array}{l}\text { Kontrol } \\
\text { Presentas } \\
\text { e (\%) }\end{array}$} \\
\hline & $\begin{array}{c}\text { Frekuen } \\
\text { si }\end{array}$ & $\begin{array}{l}\text { Present } \\
\text { ase (\%) }\end{array}$ & $\begin{array}{c}\text { Frekuen } \\
\text { si }\end{array}$ & \\
\hline $\begin{array}{l}\text { Sangat } \\
\text { Ringan }\end{array}$ & 7 & $63.6 \%$ & 0 & 0 \\
\hline Ringan & 4 & $36.4 \%$ & 1 & $9.1 \%$ \\
\hline $\begin{array}{l}\text { Ringan/ } \\
\text { Sedang }\end{array}$ & 0 & 0 & 2 & $18.2 \%$ \\
\hline Sedang & 0 & 0 & 8 & $72.7 \%$ \\
\hline Total & 11 & 100.0 & 11 & 100.0 \\
\hline
\end{tabular}

Berdasarkan table 4 pada kelompok ekperimen sebagian besar responden sesudah dioles minyak zaitun mengalami derajat ruam popok yaitu sangat ringan 7 anak $(63.6 \%)$ dan derajat ruam popok ringan 4 anak (36.4\%). Sedangkan pada kelompok control sebagian besar responden mengalami derajat ruam popok sedang 8 anak (72.7\%), ringan/sedang 2 anak (18.2\%) dan ringan 1 anak (9.1\%).

Sebagian besar responden berusia 12 bulan (27.3\%). Insiden ruam popok di Indonesia mencapai 7-35\%, yang menimpa bayi laki-laki dan perempuan berusia dibawah tiga tahun (Aisyah, 2018). Begitu juga kejadian ruam popok di china pada anak 0-36 bulan (Li, Zhu, \& Dai, 2012). Sebagian besar responden berjenis kelamin laki-laki sebesar 54.5\%. Hal ini senada dengan hasil penelitian Jelita, 2014 bahwa ruam popok banyak terjadi pada anak laki-laki sebesar $54.5 \%$ dibandingkan dengan anak perempuan (Jelita, Asih, \& Nurulita, 2014). Pada kelompok eksperimen sebagian besar responden sebelum dioles minyak zaitun mengalami derajat ruam popok yaitu ringan/sedang 63.6\%. Sedangkan pada kelompok control sebagian besar responden sebelum dioles minyak zaitun mengalami derajat ruam popok yaitu ringan/sedang $90.9 \%$. Tanda dan gejala ruam popok bervariasi dari yang ringan sampai yang berat. Pada gejala awal kelainan derajat ringan seperti kemerahan ringan di kulit pada daerah sekitar penggunaan popok yang bersifat terbatas (Lokanata, 2004). Pada kelompok ekperimen sebagian besar responden sesudah dioles minyak zaitun mengalami derajat ruam popok yaitu sangat ringan $63.6 \%$ sedangkan pada kelompok control sebagian besar responden mengalami derajat ruam popok sedang $72.7 \%$. Kandungan vitamin E dan asam lemak yang ada pada minyak zaitun dapat digunakan untuk merawat kulit guna mencegah kejadian kerusakan kulit (Fajriyah, Andriani, \& Fatmawati, 2015).

\section{Analisis Bivariat}

Menunjukkan terdapat 13 orang setelah dioles minyak zaitun derajat ruam popok memnunjukkan perbaikan dari pada sebelum dioles, 7 orang lebih parah dan 2 orang dengan derajat ruam popok sama seperti sebelum dioles minyak zaitun. Hasil uji Wilcoxon, diperoleh angka significancy 0.007 , karena nilai $p<0.05$ dapat disimpulkan ada perbedaan bermakna antara olesan minyak zaitun dan penggunaan popok kain terhadap derajat ruam popok pada anak 0-24 bulan di RSUD Goetheng Tarunadibrata Purbalingga.

Hasil uji dengan Wilcoxon membuktikan adanya pengurangan derajat ruam popok sebelum dan setelah dioleskan selama 3 hari yang dibiarkan dulu selama 20 menit di kemaluan sesudah mandi pada sore dan pagi hari selama dua kali sehari menunjukkan Ho ditolak, yang dapat dilihat pada $p$ value 0,007 lebih kecil dari 0,05. Sehingga ada perbedaan bermakna antara olesan minyak zaitun dan penggunaan popok kain terhadap derajat ruam popok pada anak 0-24 bulan.

Minyak zaitun efektif untuk mengatasi masalah kulit, seperti pada penderita kusta. Hasil penelitian yang dilakukan Fajriyah, dkk tentang efektivitas minyak zaitun untuk pencegahan kerusakan kulit pada pasien kusta bahwa keadaan kulit penderita kusta sebelum dilakukan intervensi pemberian minyak zaitun yang tidak mengalami kerusakan kulit sebanyak 8 responden $(53,3 \%)$ dan yang mengalami kerusakan kulit sebanyak 7 responden (46,7\%). Keadaan kulit penderita kusta sesudah dilakukan intervensi pemberian minyak zaitun yang tidak mengalami kerusakan kulit sebanyak 14 responden (93,3\%) dan yang masih mengalami kerusakan kulit sebanyak 1 responden $(6,7 \%)$. Memberikan olesan minyak zaitun dapat merawat kulit sebagai usaha untuk mencegah kulit yang rusak, 
dikarenakan kandungan yang ada pada minyak zaitun berupa lemak asam, vitamin $E$ yang bermanfaat untuk anti oksidan alami dan membantu menjaga struktur sel dan membrane sel sebagai akibat kerusakan karena radikal bebas. Vitamin $\mathrm{E}$ berfungsi sebagai pelindung dari kerusakan bagi sel darah merah yang berperaan dalam pengangkutan oksigen untuk semua jaringan tubuh. Vitamin E bermanfaat untuk mempersingkat luka agar cepat sembuh, mencegah proses penuaan dini, menjaga kulit tetap lembab dan menambah elastisitas kulit (Fajriyah et al., 2015).

Berdasarkan penelitian Jelita, dkk tahun 2014 bahwa dengan uji Wilcoxon 0,011 (< 0,05 ) didapatkan bahwa minyak zaitun mempunyai pengaruh dalam pengurangan derajat ruam popok pada anak umur 0-36 bulan yang mengalami diare dan menggunakan diapers. Minyak zaitun berfungsi memperbaiki regenerasi kulit, membuat kulit tetap elastis serta menjaga kulit dalam keadaan lembut (Jelita et al., 2014). Minyak zaitun merupakan minyak yang ada pada saat zaman mesir kuno dan merupakan hasil dari perasan buah zaitun dan dianggap sebagai minyak suci dan memiliki kandungan vitamin dan mineral (ROFINGAH, 2016).

Menurut penelitian Sujatni, 2012, didapatkan hasil antara lamanya pemakaian diapers dengan ruam popok diperoleh bayi yang memakai diapers selama 4 jam yang mengalami ruam popok lebih banyak yaitu $8 \%$ dibandingkan bayi yang memakai diapers selama 2 jam yaitu $8 \%$, untuk uji statistic diperoleh nulai $p=0,356$ yang berarti $p>0,05$ sehingga tidak ada pengaruh antara lamanya pemakaian diapers terhadap ruam popok pada anak (Sujatni, Hartini, \& Kusuma, 2013).

Penelitian yang dilakukan Apriza tahun 2017 dengan hasil penelitian bahwa sebelum pemberian minyak zaitun (olive oil) ruam popok pada bayi paling banyak pada derajat sedang yaitu 10 responden $(66.7 \%)$ sedangkan sesudah pemberian minyak zaitun (olive oil) ruam popok pada bayi paling banyak pada derajat ringan yaitu 7 responden (46.6\%). Uji t-test dependent menunjukkan nilai $\mathrm{P}$ value $=0,000(\leqslant$ $0,05)$. Sehingga dapat disimpulkan bahwa ada pengaruh pemberian minyak zaitun (olive oil) terhadap ruam popok pada bayi di
RSUD Bangkinang tahun 2016 (APRIZA, 2017).

\section{Kesimpulan}

Minyak zaitun dapat digunakan sebagai therapy nonfarmakologi dalam mengatasi derajat ruam popok baik di Puskesmas dan jaringannya serta di Rumah Sakit.

\section{Ucapan Terima Kasih}

Terima kasih diucapkan kepada Poltekkes Kemenkes Semarang yang telah memberikan dana untuk penelitian ini.

\section{Daftar Pustaka}

Aisyah, S. (2018). Hubungan Pemakaian Diapers Dengan Kejadian Ruam Popok Pada Bayi Usia 6-12 Bulan. Jurnal Kebidanan, 8(1), 8.

Apriza, A. (2017). Pengaruh Pemberian Minyak Zaitun (Olive Oil) Terhadap Ruam Popok Pada Bayi Di Rsud Bangkinang Tahun 2016. Jurnal Ners, 1(2).

Blume - Peytavi, U., Hauser, M., Lünnemann, L., Stamatas, G. N., Kottner, J., \& Garcia Bartels, N. (2014). Prevention Of Diaper Dermatitis In Infants-A Literature Review. Pediatric Dermatology, 31(4), 413-429.

Fajriyah, N. N., Andriani, A., \& Fatmawati, F. (2015). Efektivitas Minyak Zaitun Untuk Pencegahan Kerusakan Kulit Pada Pasien Kusta. Jurnal IImiah Kesehatan (Jik), 7(1).

Jelita, M. V., Asih, S. H. M., \& Nurulita, U. (2014). Pengaruh Pemberian Minyak Zaitun (Olive Oil) Terhadap Derajat Ruam Popok Pada Anak Diare Pengguna Diapers Usia 0-36 Bulan Di Rsud Ungaran Semarang. Karya Ilmiah.

Li, C., Zhu, Z., \& Dai, Y. (2012). Diaper Dermatitis: A Survey Of Risk Factors For Children Aged 1-24 Months In China. Journal Of International Medical Research, 40(5), 1752-1760.

Lokanata, M. D. (2004). Eksim Pada Bayi Dan Anak. Jakarta: Fakultas Kedokteran Universitas Indonesia.

Rofingah, H. (2016). Efektifitas Penggunaan Minyak Zaitun Dalam Kombinasi Pijat Woolwich Dan Endorphin Pada Kelancaran Asi Ibu Nifas Ny. F Umur 


\section{JURNAL SAINS KEBIDANAN}

19 Tahun Di Bpm Djumi Widarti Sampang Sempor Kebumen. Stikes Muhammadiyah Gombong.

Sujatni, R. A., Hartini, S., \& Kusuma, M. A. B. (2013). Pengaruh Lamanya Pemakaian Diapers Terhadap Ruam Diapers Pada Anak Diare Usia 6-12 Bulan Di Rsud Tugurejo Semarang. Karya IImiah.

Yonezawa, K., Haruna, M., Shiraishi, M., Matsuzaki, M., \& Sanada, H. (2014). Relationship Between Skin Barrier Function In Early Neonates And Diaper Dermatitis During The First Month Of Life: A Prospective Observational Study. Pediatric Dermatology, 31(6), 692-697. 